\title{
IMPACT OF ORAL HYGIENE INSTRUCTIONS ON PLAQUE INDEX IN ADOLESCENTS
}

\author{
Mirko Soldo ${ }^{1}$, Jurica Matijević ${ }^{2}$ Ana Malčić Ivanišević ${ }^{2}$ Ivana Čuković-Bagić ${ }^{3}$, Luc Marks ${ }^{4}$, Daša Nikolov Borić5, \\ Silvana Jukić Krmek² \\ ${ }^{1}$ Department of Orthodontics, School of Dental Medicine, University of Zagreb, Zagreb, Croatia \\ 2Department of Endodontics and Restorative Dentistry, School of Dental Medicine, University of Zagreb, Zagreb, Croatia \\ ${ }^{3}$ Department of Paediatric and Preventive Dentistry, School of Dental Medicine, University of Zagreb, Zagreb, Croatia \\ ${ }^{4}$ Centre for Special Care in Dentistry, Ghent University Hospital, Ghent, Belgium \\ ${ }^{5}$ Health Centre Zagreb, Zagreb, Croatia
}

\section{SUMMARY}

Objective: The objective of the study, which consisted of a motivational lecture and hands-on training, was to evaluate the role of oral hygiene education for adolescents.

Methods: The study population included sixty-two high school students between fourteen and fifteen years of age (thirty males and thirty-two females). The response rate was $76.5 \%$. The measurement of oral hygiene level was performed using the modified Green Vermilion Index (GVI). The values were recorded at baseline, one week, three months, and six months after education through motivational lecture and hands-on training was performed. Descriptive and nonparametric statistical methods were used in statistical analysis. Level of significance was 0.05 .

Results: At the beginning of the study, the GVI of all examined subjects was $3.52(\mathrm{SD}=0.70)$. One week after the motivational lecture and training, it decreased to $2.64(S D=0.69)$. Three months later, the level of plaque index had the lowest value $(1.44 ; S D=0.66)$. At the end of the study the level of plaque index increased to $2.52(S D=0.86)$.

Conclusions: A significant oral hygiene improvement in adolescents as a result of education was presented. However, due to a decline in oral hygiene level six months after the education, there is a need for educational programmes continuity.

Key words: adolescents, motivation, oral hygiene, dental plaque index

Address for correspondence: J. Matijević, Department of Endodontics and Restorative Dentistry, School of Dental Medicine, University of Zagreb, Gundulićeva 5, 10000 Zagreb, Croatia. E-mail: matijevic@sfzg.hr

https://doi.org/10.21101/cejph.a5066

\section{INTRODUCTION}

Diseases of the oral cavity are among the most common health problems. They include the most widespread diseases, like dental caries and periodontal diseases that affect all populations and age groups (1). Both infections have a multifactorial aetiology. To reduce the risk of their development, healthy behaviour, such as mechanical removal of plaque and proper dietary habits, should be adopted (2-4). Plaque control is one of the most important factors in preventing oral diseases. The accumulation of plaque is required for the development of caries and periodontal diseases (5). Therefore, maintaining good oral hygiene is the main goal of oral diseases prevention. For the level of plaque to be as low as possible, patients should be motivated and educated on the proper way of maintaining oral hygiene, and this can be achieved through education programmes on the importance of oral hygiene (6).

One of the key points in educational programmes is estimating the most appropriate age at which the information is being transferred to the attendees of such programmes (7). It had been presumed that education should begin as soon as possible, at a very young age, in order to achieve a better outcome (8). However, there is a lack of strong evidence that primary school-based behavioural interventions for reducing caries are efficient (9). Apart from this, it has been shown that relatively stable behavioural norms, including that concerning oral hygiene maintenance, could be accepted during the period of adolescence $(10,11)$. During that period, youngsters develop abstract thinking and are able to understand the concept of health. They can relate health with their own behaviour and can adapt their behaviour towards health improvement (12). On the other hand, during adolescence a youngster often confronts his/ her authorities, and some studies recognize this period as the most difficult one for education on oral health $(13,14)$. Furthermore, adolescents tend to underestimate the risks, consider themselves less vulnerable, and are less aware of the possibility of oral diseases development (15). In addition, it was shown that by far most adolescents brush their teeth for aesthetic purposes and only a small number of them to prevent oral diseases (16).

In countries which lack national dental caries prevention programmes there is a great need for strategy and planning of such programmes from pregnancy until the end of education. Development and implementation of oral health preventive programmes should consider an overall approach targeting those parts of population which are susceptible to acceptance of new positive habits. 
The purpose of this research is to determine whether the level of dental plaque and maintenance of oral hygiene are influenced by motivation and education of adolescents on the importance of oral health, as well as by instructions on proper brushing techniques. The null hypothesis was that education and motivation would not influence the status of oral health.

\section{MATERIALS AND METHODS}

The research set up was approved by the Ethics Committee of School of Dental Medicine at the University of Zagreb and Department of Secondary Education, Ministry of Science, Education and Sports of the Republic of Croatia (Class 602-01/11-01/00009, No. 533-09-11-0004). The study included an informed consent signed by both adolescents and their parents. Parents and participants could withdraw from the research at any time without giving any justification to the examiner.

The examination group consisted of 62 first-grade high school students. Respondents ranged from 14.2 to 16.3 years of age, i.e. mean age 15.3 . Thirty of them were males $(48.4 \%)$ and 32 females (51.6\%). The response rate was 76.5 percent.

A 60-minute lecture on oral hygiene was held. It consisted of two parts: lecture and hands-on training. The topic of the lecture was related to oral and dental diseases, the importance of their prevention, and proper methods of oral hygiene. After the lecture, a hands-on training was given presenting the students with the proper brushing technique (a modified technique by Bass) and dental floss use on models. The subjects were then given toothbrushes and dental floss and practiced proper tooth brushing and flossing on themselves under professional supervision.

\section{Dental Plaque Measurement}

Four measurements were performed on each subject. The first, baseline measurement was performed before any education started.

The second measurement was performed one week after education, the third one was done three months after education and the last measurement was done six months after education.

The students' dental plaque values (DPVs) were measured by the modified Green-Vermillion Index (GVI) using dental plaque revelator (Plaque Test - Ivoclar Vivadent AG, Schaan, Liechtenstein) (17). Dental plaque buildup coloured with plaque revelator became fluorescent under the blue light lamp, making it visible without subsequent teeth staining. Dental arches were divided into sextants, three in each jaw. DPVs on vestibular and oral sides were determined, and the highest value in the sextant was recorded. DPVs were expressed with numbers from 0 to 3 . Zero denoted the absence of plaque, one denoted that less than one third of the tooth surface was covered with plaque, two denoted that more than one and less than two-thirds of the tooth surface was covered with plaque, and three denoted that more than two thirds of the measured tooth surface was covered with plaque. The modified GVI used in the study is in fact debris index - the first part of the original Green and Vermillion oral hygiene index (OHI) (17). The modification of original $\mathrm{OHI}$ i.e. the omission of calculus index was employed in this study, because of the setting where the examinations and recordings were performed. Measurements were carried out at the First High School in Zagreb. Screening was always performed in the morning, between 8 a.m. and 10 a.m., before the first school meal. For that purpose, a dental mirror and a curing lamp Bluephase C8 Light Unit (Ivoclar Vivadent AG, Schaan, Liechtenstein) were used. The authors found it difficult in the school setting to differentiate between calculus and plaque, since only visual method was employed during recordings.

DPVs for all subjects were recorded by the main examiner which was previously calibrated. For calibration, two measurements were performed with one-hour interval on ten randomly selected students by three examiners until an 85 percent agreement was obtained. One week after calibration ten randomly selected patients were re-evaluated by all three examiners and Cronbach's alpha was calculated for the whole sample (0.79).

The data were entered in customized forms recommended by the authors of the GVI (17).

\section{Statistical Analysis}

The data were entered into a computerized database (MS Access-Microsoft Office). The statistical analysis was performed using an SPSS ver. 17 (IBM, Chicago, IL, USA) by means of descriptive and nonparametric statistics including Friedmann test, Mann Whitney test and Wilcoxon signed ranks test. Statistical significance level was 0.05 .

\section{RESULTS}

The mean GVI value for all subjects at baseline was 3.52 $(\mathrm{SD}=0.70)$, and it decreased to $2.52(\mathrm{SD}=0.86)$ after six months. One week after education, the mean GVI value was 2.64 $(\mathrm{SD}=0.69)$, and three months after it was $1.44(\mathrm{SD}=0.66)$. Table 1 shows mean modified GVI values per sextant for all subjects, for all measurements. Distribution of modified GVI values between males and females and between the four measurements was significantly different (Friedmann test, $\mathrm{p}<0.05$ ).

Prior to the oral hygiene instructions, the male part of the population had significantly higher GVI values compared to the female population in the following sextants: upper right oral (Mann-Whitney $\mathrm{U}=317.000, \mathrm{Z}=-2.658, \mathrm{p}=0.008$ ), upper frontal labial (Mann-Whitney $U=286.000, Z=-2.992, p=0.003$ ), upper left buccal (Mann-Whitney $U=341.500, Z=-2.090, p=0.037$ ), lower frontal labial (Mann-Whitney $U=329.000, Z=-2.402$, $p=0.016$ ), while the female population had a significantly higher GVI value in the lower right buccal sextant (Mann-Whitney $\mathrm{U}=329.500, \mathrm{Z}=-2.254, \mathrm{p}=0.024)$. The second measurement revealed males having higher scores in upper frontal labial (Mann-

Table 1. Mean Green-Vermillion plaque index values for the whole population at four measurements $(N=62)$

\begin{tabular}{|l|c|c|c|c|}
\hline & Minimum & Maximum & Mean & $\begin{array}{c}\text { Std. } \\
\text { deviation }\end{array}$ \\
\hline First measurement & 2.17 & 5.83 & 3.52 & 0.70 \\
\hline Second measurement & 1.33 & 4.33 & 2.64 & 0.69 \\
\hline Third measurement & 0.00 & 2.67 & 1.44 & 0.66 \\
\hline Fourth measurement & 0.00 & 4.17 & 2.52 & 0.86 \\
\hline
\end{tabular}


Whitney $\mathrm{U}=352.000, \mathrm{Z}=-2.119, \mathrm{p}=0.034)$ and lower frontal labial (Mann-Whitney $U=336.500, Z=-2.411, p=0.016$ ) sextants. The third measurement showed that there was a difference only in upper frontal labial sextants (Mann-Whitney $U=342.000$, $\mathrm{Z}=-2.001, \mathrm{p}=0.045)$, while the fourth measurement revealed differences in upper frontal labial (Mann-Whitney $U=295.500$, $\mathrm{Z}=-2.578, \mathrm{p}=0.01$ ) and lower right buccal (Mann-Whitney $\mathrm{U}=316.000, \mathrm{Z}=-2.315, \mathrm{p}=0.021$ ) sextants.

Mean GVI values for the entire population after the instructions on oral hygiene divided by compliant sextant, jaw and tooth surfaces are shown in Table 2 and Table 3.

The difference in mean GVI values per sextant (total value of buccal and oral plaque indices divided by the number of sextants -6) for the entire population before and after instructions on oral hygiene was statistically significant (Wilcoxon Signed Ranks test, $Z=-6.221, p<0.001)$. Significant difference between plaque values was found in all sextant/surface combinations before and after oral hygiene education (Wilcoxon Signed Ranks test, $\mathrm{p}<0.01$ for all combinations). Furthermore, there was a significant difference between the first and the third measurement (Wilcoxon Signed Ranks test, $\mathrm{Z}=-6.849, \mathrm{p}<0.001)$, the first and the fourth measurement (Wilcoxon Signed Ranks test, $Z=-6.108, p<0.001$ ), the second and the third measurement (Wilcoxon Signed Ranks test, $\mathrm{Z}=-6.500, \mathrm{p}<0.001$ ), and the third and the fourth measurement (Wilcoxon Signed Ranks test, $Z=-6.061, \mathrm{p}<0.001$ ). However, no significant difference existed between the second and the fourth measurement (Wilcoxon Signed Ranks test, $Z=-1.027, p=0.304$ ). Finally, GVI values of corresponding surfaces (buccal, oral) of both jaws combined, showed significant improvement between the first and the fourth measurement (Fig. 1). The differences in average cumulative values GVI between the measurements are shown in Fig. 2.

\section{DISCUSSION}

Motivating and educating patients on the proper way of maintaining adequate oral hygiene remains a major professional challenge for dentists and oral hygienists in general. Numerous studies have confirmed the major importance and impact of educational

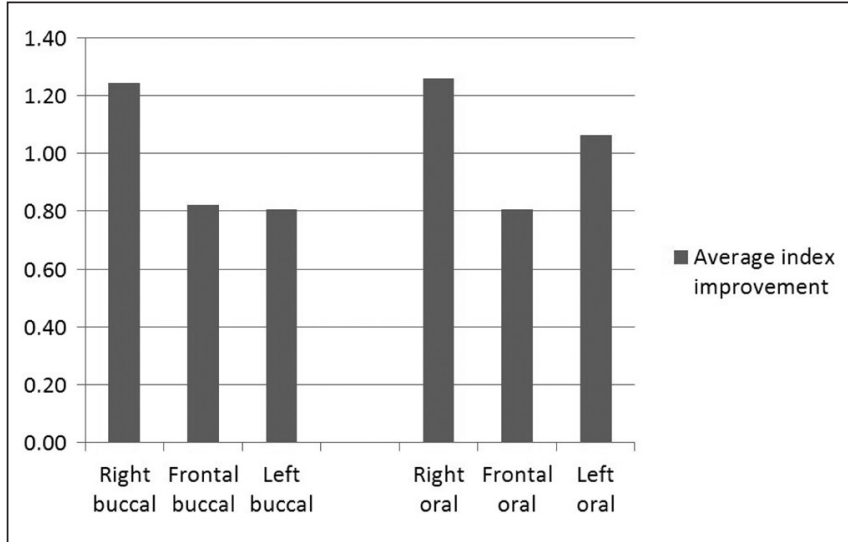

Fig. 1. Mean modified GVI values of corresponding surfaces (buccal, oral) of both jaws combined.

The improvement between the first and the fourth measurement was significant.

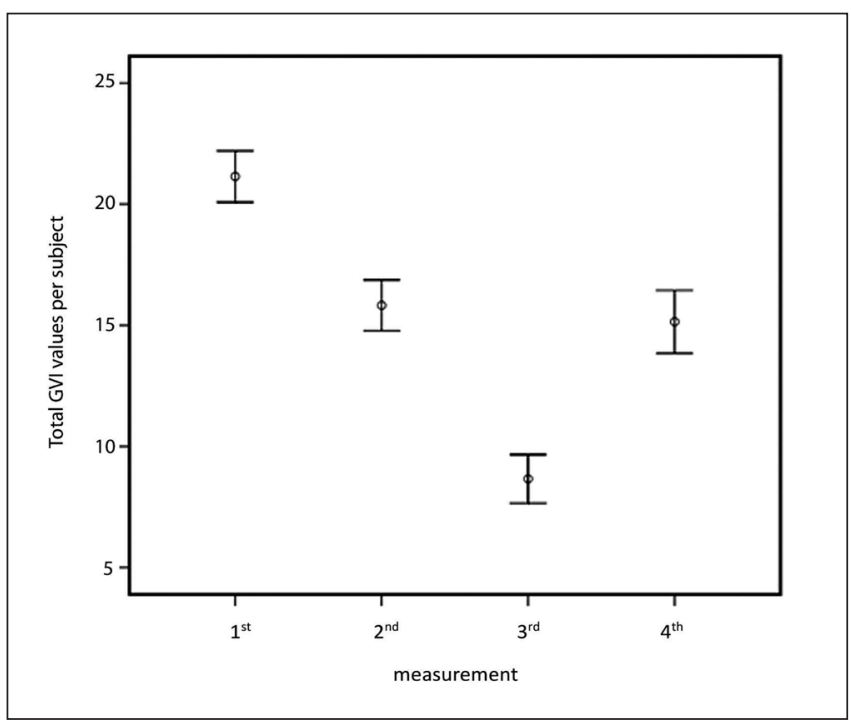

Fig. 2. Mean cumulative modified GVI values between four measurements.

1 - baseline measurement; 2 - one week after education and motivation; 3 - three months after education and motivation; 4 - six months after education and motivation.

Table 2. Modified Green-Vermillion plaque index values of combined upper and lower jaw surfaces after hygiene instructions (2nd measurement) $(N=62)$

\begin{tabular}{|l|c|c|c|c|c|c|}
\hline & $\begin{array}{c}\text { Right buccal } \\
\text { sextants }\end{array}$ & $\begin{array}{c}\text { Right oral } \\
\text { sextants }\end{array}$ & $\begin{array}{c}\text { Frontal labial } \\
\text { sextants }\end{array}$ & $\begin{array}{c}\text { Frontal oral } \\
\text { sextants }\end{array}$ & $\begin{array}{c}\text { Left buccal } \\
\text { sextants }\end{array}$ & Left oral sextants \\
\hline Mean & 3.02 & 2.97 & 2.02 & 1.89 & 3.06 & 2.38 \\
\hline Std. error & 0.18 & 0.13 & 0.16 & 0.11 & 0.16 & 0.13 \\
\hline Std. deviation & 1.42 & 1.04 & 1.25 & 0.86 & 1.31 & 1.02 \\
\hline
\end{tabular}

Table 3. Mean modified Green-Vermillion plaque index values for all sextants per jaw, division per surfaces, after hygiene instructions (2nd measurement) ( $N=62)$

\begin{tabular}{|l|c|c|c|c|}
\hline & Upper jaw buccal & Upper jaw oral & Lower jaw buccal & Lower jaw oral \\
\hline Mean & 4.52 & 2.92 & 3.58 & 4.31 \\
\hline Std. error & 0.25 & 0.13 & 0.19 & 0.19 \\
\hline Std. deviation & 2.04 & 1.03 & 1.55 & 1.55 \\
\hline
\end{tabular}


and motivational programmes (18-20). Difficulties in changing behaviour and patient awareness towards good oral hygiene are major public health problems. It was found that patients who have lived all their lives with poor oral hygiene find it difficult to increase awareness on the importance of oral hygiene, and to change their attitude and behaviour towards it (20). Studies confirm that the first step in changing behaviour is to educate and instruct patients suggesting that a properly educated patient can understand the importance of maintaining good oral hygiene $(21,22)$.

In the research presented, statistically significant GVI reduction after education and motivation in both jaws and all sextants was recorded. Since the modified GVI used in this study did not include calculus index from the original $\mathrm{OHI}$ by Greene and Vermillion (17) due to the school setting characteristics, absolute GVI values recorded cannot be compared with $\mathrm{OHI}$ values in other studies. However, relative values can be compared, and the observed reduction after education is in concordance with the findings in other studies $(6,20,23)$. The difference in the initial plaque index between male and female population was noticed, in favour of the female population. This can be explained by more frequent teeth brushing by females (11). Gender differences may result from higher dental aesthetic expectations in case of females. This peer-related and social pressure may result in increased attention to hygiene (24). However, from the screening results it is clear that gender differences declined as a result of the given education and oral hygiene instructions.

No data on the dexterity of the subjects was collected. Considering that the majority of population is right-handed, it may be the cause of the baseline results of the right buccal surfaces. However, it should be noted that at the end of the study, highest values were recorded on the left buccal segment, so the dexterity of the participants may have controversial impact on plaque indices and deserves further attention.

Motivation was noted to decrease over time, causing a gradual new increase in the value of GVI (25). Some studies suggest that oral health prevention programmes should be a continuous process, rather than a brief spell project, and emphasize the importance of continuous motivation and periodic re-evaluation (20, 25-27). Nevertheless, it was reported that the improvement in oral hygiene lasted for three and a half years (28). Our results showed an increase of plaque values at six-month recall compared to the initial plaque score after education and instructions. However, despite the negative trend, after the fourth measurement the level of oral hygiene was still better than it had been prior to the oral health lecture and instructions session.

Recording plaque indices before and after the education offers the opportunity to motivate each examinee individually, pointing to the specific sextants which scored worse. In addition to theoretical education, giving precise instructions on oral hygiene techniques using a model, along with an individual approach to every subject, was shown to have a major role in achieving better results (18, 29). Furthermore, plaque index scores after the education give valuable feedback information to educators on the effectiveness of their programmes. Different rates of success of educational programmes were reported $(25,28,30)$. This may be explained by different study designs used in these programmes (18).

Reduction of GVI after instructions on tooth brushing techniques, and additional individual approach, suggests that the brushing techniques practiced by our respondents prior to our instructions were incorrect, or at least less effective in removing plaque. Therefore, since adolescence appears to be the age at which the effects of education may come to full expression, the development and implementation of preventive programmes for adolescents should be considered at a national level. In addition, this research emphasizes the importance of long-term re-evaluation and subsequent re-education due to a decline in oral hygiene level.

\section{CONCLUSION}

Based on the results of this study, it can be concluded that adolescents are susceptible to acceptance of new positive oral hygiene habits while GVI values decreased significantly after their education. Therefore, motivating, instructing and educating adolescents on the importance of oral hygiene, along with demonstrating proper tooth brushing techniques, should be included in national preventive programmes. Educational programmes should be performed continuously to prevent possible decline in performing oral hygiene measures.

\section{Acknowledgement}

This work was part of projects supported by the Ministry of Science, Education and Sports of the Republic of Croatia, No. 065-0650445-0434 and No. 065-0650445-0408.

\section{Conflict of Interests}

None declared

\section{Authors' Contribution}

MS - design and study performance, hypothesis, writing the manuscript; JM - study performance, statistical analysis, manuscript review; AMI study performance, writing the manuscript; IČB - writing the manuscript, consultations in data analysis and explanation, manuscript review; LM - manuscript review, consultations in data analysis and explanation; SJK - study design and performance, hypothesis, writing the manuscript, research organization.

\section{REFERENCES}

1. Petersen PE. The World Oral Health Report 2003: continuous improvement of oral health in the 21 st century - the approach to the WHO Global Oral Health Programme. Community Dent Oral Epidemiol. 2003;31(Suppl 1):3-24.

2. Sheiham A. Dietary effects on dental diseases. Public Health Nutr. 2001;4(2B):569-91.

3. Achembong LN, Kranz AM, Rozier RG. Office-based preventive dental program and statewide trends in dental caries. Pediatrics. 2014;133(4):e827-34.

4. Julihn A, Barr Agholme M, Grindefjord M, Modéer T. Risk factors and risk indicators associated with high caries experience in Swedish 19-yearolds. Acta Odontol Scand. 2006;64(5):267-73.

5. Axelsson P, Nyström B, Lindhe J. The long-term effect of a plaque control program on tooth mortality, caries and periodontal disease in adults. Results after 30 year of maintenance. J Clin Periodontol. 2004;31(9):749-57.

6. Zanin L, Meneghim MC, Assaf AV, Cortellazzi KL, Pereira AC. Evaluation of an educational program for children with high risk of caries. $\mathrm{J}$ Clin Pedriatr Dent. 2007;31(4):246-50.

7. Petrie J, Bunn F, Byrne G. Parenting programmes for preventing tobacco, alcohol or drugs misuse in children $<18$ : a systematic review. Health Educ Res. 2007;22(2):177-91. 
8. Finlayson TL, Siefert K, Ismail AI, Sohn W. Maternal self-efficacy and 1-5-year-old children's brushing habits. Community Dent Oral Epidemiol. 2007;35(4):272-81.

9. Cooper AM, O'Malley LA, Elison SN, Armstrong R, Burnside G, Adair P, Dugdill L, Pine C. Primary school-based behavioural interventions for preventing caries. Cochrane Database Syst Rev. 2013;5:CD009378. doi: 10.1002/14651858.CD009378.pub2.

10. Åström AN. Stability of oral health-related behaviour in a Norwegian cohort between the ages of 15 and 23 years. Community Dent Oral Epidemiol. 2004;32(5):354-62.

11. Kuusela S, Honkala E, Rimpelä A, Karvonen S, Rimpelä M. Trends in toothbrushing frequency among Finnish adolescents between 1977 and 1995. Community Dent Health. 1997;14(2):84-8.

12. Susman EJ, Dorn LD, Feagans LV, Ray WJ. Historical and theoretical perspectives on behavioural health in children and adolescents: an introduction. In: Suman EJ, Feagans LV, Ray WJ, editors. Emotion, cognition, health, and development in children and adolescents. London: Psychology Press; 1992. p. 1-8.

13. Routh DK. Prevention and lifestyle in child health psychology. In: Melamed BG, Matthews KA, Routh DK, Stabler B, Schneiderman N, editors. Child Health Psychology. New Jersey: Lawrence Erlbaum Associates; 1988. p. 5-15.

14. Binder K. Psychological foundations of dental health education in children. Int Dent J. 1981;31(4):261-6.

15. Radius SM, Dillman TE, Becker MH, Rosenstock IM, Horvath WJ. Adolescent perspectives on health and illness. Adolescence. 1980;15(58):37783

16. Macgregor ID, Balding JW. Toothbrushing frequency and personal hygiene in 14-year-old schoolchildren. Br Dent J. 1987;162(4):141-4.Greene JC, Vermillion JR. Oral Hygiene Index [Internet]. Malmö: Collaborating Center for Education, Training and Research in Oral Health [cited 2013 Jan 20]. Available from: http://www.whocollab.od.mah.se/expl/ohigv60. html

17. Leal SC, Bezerra AC, Toledo OA. Effectiveness of teaching methods for toothbrushing in preschool children. Braz Dent J. 2002;13(2):133-6.

18. Peng B, Peterson PE, Fan MW, Tai BJ. Oral health status and oral health behaviour of 12-year-old urban schoolchildren in the People's Republic of China. Community Dent Health. 1997;14(4):238-44.
19. Rodrigues JA, dos Santos PA, Baseggio W, Corona SA, Palma-Dibb RG, Garcia PP. Oral hygiene indirect instruction and periodic reinforcement effects on index plaque in schoolchildren. J Clin Pediatr Dent. 2009;34(1):31-4.

20. Christensen GJ. Special oral hygiene and preventive care for special needs. J Am Dent Assoc. 2005;136(8):1141-3.

21. Kanellis MJ. Caries risk assessment and prevention: strategies for head start, early head start and WIC. J Public Health Dent. 2000;60(3):210-7.

22. Hausen $H$. Oral health promotion reduces plaque and gingival bleeding in the short term. Evid Based Dent. 2005; 6(2):31.

23. Geron S, Atalia W. Influence of sex on the perception of oral and smile esthetics with different gingival display and incisal plane inclination. Angle Orthod. 2005;75(5):778-84.

24. Ivanovic M, Lekic P. Transient effect of a short-term educational program without prophylaxis on control of plaque and gingival inflammation in school children. J Clin Periodontol. 1996;23(8):750-7.

25. Tolvanen M, Lahti S, Hausen H. Changes in toothbrushing frequency in relation to changes in oral health-related knowledge and attitudes among children - a longitudinal study. Eur J Oral Sci. 2010;118(3):284-9.

26. Freitas-Fernandes LB, Novaes AB Jr, Feitosa AC, Novaes AB. Effectivness of an oral hygiene program for Brazilian orphans. Braz Dent J. 2002;13(1):44-8.

27. Tolvanen M, Lahti S, Poutanen R, Seppä L, Pohjola V, Hausen H. Changes in children's oral health-related behaviour, knowledge and attitudes during a 3,4-yr randomized clinical trial and oral health-promotion program. Eur J Oral Sci. 2009;117(4):390-7.

28. Okada M, Kuwahara S, Kaihara Y, Ishidori H, Kawamura M, Miura K, et al. Relationship between gingival health and dental caries in children aged 7-12 year. J Oral Sci. 2000;42(3):151-5.

29. Brukiene V, Aleksejüniene J. An overview of oral health promotion in adolescents. Int J Paediatr Dent. 2009;19(3):163-71.

Received February 8, 2017 Accepted in revised form March 11, 2020 